Viso - Cadernos de estética aplicada Revista eletrônica de estética

ISSN 1981-4062

$N^{0} 15,2014$

http://www.revistaviso.com.br/

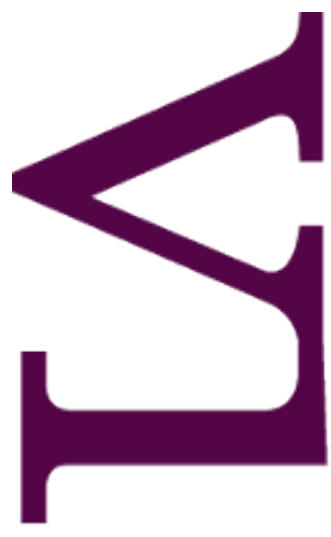

r
0
$Z$

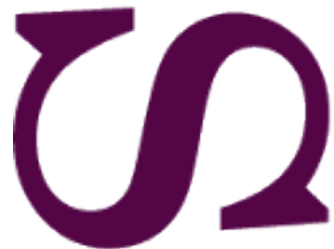

$\varangle$

4

$\underline{\underline{u}}$

$\frac{a}{4}$

$\varangle$

$\underline{\underline{U}}$

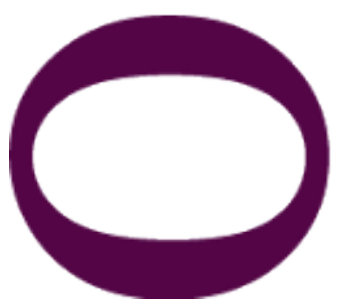

\title{
Temporalidade e arte: a eternidade frágil de Casanova Pedro Duarte
}




\section{RESUMO}

Temporalidade e arte: a eternidade frágil de Casanova

Esse artigo é uma réplica ao texto de Marco Antonio Casanova intitulado "Eternidade frágil: tempo existencial e abstração".

Palavras-chave: tempo - pintura - Klee - Pollock

\section{ABSTRACT}

Temporality and Art: Casanova's Fragile Eternity

This paper is a critical response to Marco Antonio Casanova's "Fragile Eternity: Existential Time and Abstraction"

Keywords: time - painting - Klee - Pollock 


\section{DUARTE, P. "Temporalidade e arte: a eternidade frágil de Casanova". In: Viso: Cadernos de estética aplicada, v. VIII, n. 15 (jan-dez/2014), pp. 201-208.}

DOI: $10.22409 / 1981-4062 / v 15 i / 185$

Aprovado: 11.07.2014. Publicado: 31.01.2015.

(C) 2014 Pedro Duarte. Esse documento é distribuído nos termos da licença Creative Commons Atribuição-NãoComercial 4.0 Internacional (CC-BY-NC), que permite, exceto para fins comerciais, copiar e redistribuir o material em qualquer formato ou meio, bem como remixá-lo, transformá-lo ou criar a partir dele, desde que seja dado o devido crédito e indicada a licença sob a qual ele foi originalmente publicado.

Licença: http://creativecommons.org/licenses/by-nc/4.0/deed.pt_BR

Accepted: 11.07.2014. Published: 31.01.2015.

(C) 2014 Pedro Duarte. This document is distributed under the terms of a Creative Commons Attribution-NonCommercial 4.0 International license (CC-BY-NC) which allows, except for commercial purposes, to copy and redistribute the material in any medium or format and to remix, transform, and build upon the material, provided the original work is properly cited and states its license.

License: http://creativecommons.org/licenses/by-nc/4.0/ 
Gostaria de saudar, antes de começar, o formato que o Grupo de Trabalho de Estética encontrou para nossos encontros, quebrando a monótona rotina de apresentações curtas onde todos falam, e nem sempre ouvem. Com o formato em vigor agora, no qual os textos dos professores que vão falar são antecipadamente divulgados e outros dois professores ficam responsáveis por lê-lo e debatê-lo, o diálogo filosófico ganha outra consistência e renovado interesse. Foi tal contexto que me deu a tarefa, mas também a oportunidade, de ler atentamente Eternidade frágil: ensaio de temporalidade na arte ${ }^{1}$, de Marco Casanova.

Minha expectativa era encontrar um trabalho sobre a arte, mas ele não é só isso. Para quem acompanha a produção de Casanova, é possível perceber mais um passo do trajeto de reflexão que, além de tantas palestras e artigos, encontra-se no livro $O$ instante extraordinário: vida, história e valor na obra de Nietzsche ${ }^{2}$ e ainda em Nada a caminho - niilismo, impessoalidade e técnica na obra de Martin Heidegger. ${ }^{3} \mathrm{~A}$ ideia do instante extraordinário e o problema do niilismo atual são retomados em Eternidade frágil. Há menos uma ruptura que continuidade entre aqueles e este, atados todos indelevelmente aos estudos dos dois autores citados nos títulos: Nietzsche e Heidegger. É o espírito da fenomenologia, de Husserl mas sobretudo de Heidegger, que parece orientar esse caminho reflexivo trilhado até aqui, articulando as análises eruditas dos filósofos com a tentativa de lançar um olhar sobre os desafios da época atual em sua dimensão ontológica.

O que apareceu, portanto, de novo no novo livro, publicado em 2013, foi a atenção para a arte. Isso, a meu ver, torna sua terceira parte a mais instigante, já que as duas primeiras contextualizam a formação de uma filosofia da história da qual surge a filosofia da arte e o sentido do tempo na época contemporânea para, por contraste, sugerir qual é essa outra temporalidade - a eternidade frágil - que estaria na arte. É também a parte em que o livro se torna mais criativo e pessoal, ao enfrentar obras de arte específicas e lê-las num horizonte hermenêutico.

São algumas das páginas dessa parte que foram endereçadas para este VII Encontro do GT de Estética. Elas foram meu ponto de partida para o comentário que farei aqui, voltado especialmente para as questões de método, de abordagem filosófica da arte aí presente. Gostaria de ter tido tempo para debater também as análises específicas de algumas pinturas, mas fica para outra oportunidade, pois concluí que seriam pontos demais para tratarmos de tudo junto agora. Deter-me-ei, portanto, em questões que dizem respeito ao próprio modo de fazer a relação entre a análise filosófica e o fenômeno artístico. Espero cumprir, assim, o papel que me cabe, dando estímulo para pensarmos ainda mais acerca dessa relação entre filosofia e arte - tradicionalmente tão difícil, desde Platão. ${ }^{4}$

No começo do capítulo dedicado só à arte de Eternidade frágil, é afirmada, em longa passagem, a dificuldade para simplesmente olharmos uma obra. Ela é exposta da 
seguinte forma: "o que menos acontece ao nos depararmos com uma obra específica é suspendermos a quantidade enorme de informações que temos sobre a obra, sobre o seu estilo de época, sobre as intenções estéticas do autor e coisas afins". Desse modo, continua a passagem, "vamos perdendo o contato com a obra mesma e inserindo a obra como caso no interior de um quadro conceitual qualquer". Logo, a obra desapareceria e perderia seu vigor fenomenal. "O difícil, portanto, nunca é acumular conjuntos de informações sobre um quadro", lemos, "um movimento artístico ou um autor, mas antes alcançar um movimento direto e intencional de ver que abra espaço para que o quadro se mostre não no campo de mostração que emprestamos a ele, mas no campo de mostração que é o dele". Seria, portanto, "preciso ver aqui, com a particularidade que nos é peculiar, sem, contudo, impor à obra algo assim como um ponto de vista prévio". ${ }^{5}$

Essas passagens me pareceram importantes pois, embora não constem no material enviado para o GT de Estética, definem o modo de abordagem filosófico da arte que comandará o texto. Teria, então, certas questões a partir delas, que, a meu ver, incidem sobre todas as análises específicas de pinturas que ocupam as tantas páginas a seguir (inclusive aquelas sobre Paul Klee e Jackson Pollock, que são destacadas nas páginas remetidas especificamente ao GT de Estética e, mais, que ocupam um lugar de coroamento da argumentação acerca da temporalidade da arte a partir da ideia de "eternidade frágil"). Irei elencar, ponto por ponto, tais questões a partir de agora. Vamos a elas.

Embora a abordagem filosófica da arte adotada seja muito explicitamente fenomenológica, inspirada em Edmund Husserl e, sobretudo, Martin Heidegger, ou seja, em autores já do começo do século $X X$, o esforço aí mencionado de ver a obra sem a interferência dos elementos externos a ela faz lembrar muito aquela atitude que, mais de cem anos antes, Immanuel Kant chamara de "desinteresse" na sua Crítica da faculdade do juízo. ${ }^{6}$ Todas as informações eruditas e históricas sobre a arte que atrapalhariam, por serem demasiadamente externas, o contato com a obra mesma parecem fazer parte de um interesse cognitivo no fenômeno estético, que de antemão subtrai a sua singularidade independente. Quando Kant pedia que o espectador se tornasse desinteressado diante do belo, por exemplo, esse apelo era para que interesses cognitivos e morais, em primeiro lugar, mas também os pragmáticos e eruditos, ficassem de fora para que encontrássemos o que estava à nossa frente por si e em si mesmo.

Na estrutura negativa do próprio termo "desinteresse" - ou seja, um "não-interesse" parece estar admitido, implicitamente, que ver é o mais difícil, que isso exige de nós um esforço, que em geral já estamos interessados demais para somente enxergar o fenômeno estético a partir de si. Não precisamos de esforço para que tenhamos interesses, mas para nos livrarmos da projeção deles sobre aquilo com o que nos encontramos. Por isso, Kant dizia que o prazer estético era desprovido de conceitos ${ }^{7}$, isto é, ele não seria inserido em "um quadro conceitual qualquer", conforme as palavras de Eternidade frágil. Nesse sentido, aliás, é como se todo conceito fosse já um pré-conceito, 
e daí o seu caráter problemático ao ser referido à obra de arte, que é sempre, a cada vez, singular. O conceito antecipa o que, na arte, nunca pode ser antecipado - o ser específico de uma obra particular. Daí a importância da autonomia da obra de arte para considerar o seu ser.

O próprio Heidegger, em um curto mas impressionante capítulo dos seus estudos sobre Nietzsche, apontou a importância do desinteresse, como Kant teria definido, e não apenas para a estética, mas mesmo para a ontologia. Infelizmente, segundo Heidegger ${ }^{8}$, a noção de desinteresse foi equivocadamente entendida por toda a tradição do pensamento ocidental posterior - incluindo Schopenhauer e Nietzsche; exceção feita apenas a Schiller. Heidegger tenta recuperar, então, essa noção de Kant, apontando que ela nada teria a ver com seu significado vulgar de indiferença ou de frieza. Muito pelo contrário.

"Para achar algo belo, precisamos deixar o que vem ao nosso encontro vir puramente como ele mesmo é, em sua própria estatura e dignidade", observaria Heidegger, "não podemos contabilizá-lo de antemão em vista de algo diverso, de nossas metas e intuitos, um possível gozo e uma possível vantagem". ${ }^{9}$ Em suma, Heidegger concorda com Kant, aqui, que precisaríamos, diante do belo, adotar o "favor livre de constrangimento". Mais ainda, Heidegger parece conceder, ao que Kant considerava estritamente a relação estética do homem com as coisas, uma conotação mais forte e mais geral, uma conotação ontológica que definiria enfim a própria relação com ser. Não constrangê-lo para favorecer o seu aparecer.

Finalmente, tendo tudo isso em vista, a minha pergunta é se a abordagem fenomenológica de Eternidade frágil sobre a arte não seria também uma estética, no sentido de Kant. Em suma, o ver que deixa que a coisa se mostre a partir de si não é justamente aquele que se conquista através do desinteresse? O favor livre de constrangimento não é o que permite à obra o aparecer a partir de si? Não se trata, num e noutro caso, de evitar uma projeção dos conceitos prévios sobre as obras de arte? Essa seria a primeira questão (que de certo modo recupera então o debate em torno da apresentação de Virginia Figueiredo - ocorrida neste GT de Estética junto aos comentários de Luiz Camillo Osório e Bernardo Oliveira sobre ela - versando sobre o que Benedito Nunes chamou de "desestetização da arte" ${ }^{10}$ feita por Heidegger), sobre a eventual aproximação entre estética e ontologia.

Conectada a essa questão, há ainda uma outra. Eternidade frágil insiste, e muito, na explicitação de seu enfoque fenomenológico. Mesmo o estilo de escrita, às vezes, lembra o estilo de Heidegger, por exemplo. Essa presença é muito forte, e determina o sentido da totalidade do projeto do livro. Fico pensando, sob este aspecto, se a fenomenologia, contraditoriamente, não ameaçaria tornar-se, sem que nos demos conta, uma espécie de moldura conceitual prévia para se pensar a obra de arte. Embora o método fenomenológico procure a lógica do aparecer no próprio aparecer, embora ele 
busque deixar a coisa ser ou se mostrar a partir de si, será que, mesmo assim, já não há uma série de características dessa teoria (se é que poderíamos chamá-la assim) que, quando tomada tão fortemente como um norte, faz dela mesma um empecilho para favorecer livremente a singularidade de cada obra autônoma? Em outras palavras, será que eleger um método apenas de modo tão central para analisar a arte já não traria um pré-conceito?

Indo ainda além. Falar da arte não exigiria arriscar-se na linguagem sem o amparo teórico que o vocabulário de certos filósofos pode nos dar? Isso, penso, é um desafio sobre o qual nós, estudiosos de filosofia, teríamos de meditar, ao procurarmos falar de arte. $\mathrm{E}$ talvez, aqui, não se trate só de abdicar de tantos e tantos e tantos conhecimentos que temos. Não se trataria de purificar-nos das informações e do que se constituiu historicamente pela crítica de arte. Seria o caso, antes, de saber saber, como dizia Mário de Andrade. ${ }^{11}$ Ou seja, não se trata de despir nosso saber para poder ver, e sim de aprender a saber de um modo tal que não apague o ver, mas que o potencialize. Clement Greenberg, o grande crítico que soube ver como poucos a pintura de Jackson Pollock, tão importante para Eternidade frágil já ao seu fim, dizia que o melhor conselho para os jovens críticos iniciantes seria olhar, olhar e olhar. ${ }^{12}$ Sem dúvida. Mas, ele mesmo sabia mobilizar o seu saber para, na crítica, ajudá-lo na produção discursiva. Não seria também este nosso desafio?

Concluindo, sublinho que coloco a pergunta na primeira pessoa do plural pois, de fato, a faço a mim mesmo. Essas questões aqui expostas são não apenas para o Casanova, meu interlocutor, mas também a partilha de inquietações que eu mesmo tenho sobre a relação entre a filosofia e a arte. Compreendo bem certo desconforto com a ideia de "passar a vida inteira repetindo os outros", conforme disse o Casanova aqui, ou seja, com a ideia de apenas reconstruir eternamente os autores que se estuda. Entretanto, será que quando elegemos, como também foi dito, dois ou três autores - no caso, Dilthey e Heidegger - como "as posições mais fortes no relacionamento entre arte e história", não acabamos, malgrado nossas intenções, presos à sua moldura de pensamento? E Benjamin, Lukács e Adorno? Não os cito por um ímpeto de fazer justiça a tais nomes, mas por lembrar que tais autores foram atentos a muitas obras específicas na sua relação com a história, e que derivaram precisamente daquela tradição moderna de consideração sobre a própria história citada em Eternidade frágil. Será que, enfim, não teremos que, ao pensar as obras sem instrumentalizá-las como ilustração de teorias, abdicar das referências filosóficas tão determinadas?

\footnotetext{
* Pedro Duarte é professor do Departamento de Filosofia da PUC-RIO.

${ }^{1}$ CASANOVA, M. A. Eternidade frágil: ensaio de temporalidade na arte. Rio de Janeiro: Forense Universitária, 2013.
} 
2 Idem. O instante extraordinário: vida, história e valor na obra de Nietzsche. Rio de Janeiro: Forense Universitária, 2003.

${ }^{3}$ Idem. Nada a caminho - niilismo, impessoalidade e técnica na obra de Martin Heidegger. Rio de Janeiro: Forense Universitária, 2006.

${ }^{4}$ PLATÃO. A república. Belém: UFPA, 2000.

${ }^{5}$ CASANOVA, M. A. Eternidade frágil: ensaio de temporalidade na arte. Op. cit., p. 298.

${ }^{6}$ KANT, I. Crítica da faculdade do juízo. Rio de Janeiro: Forense Universitária, 1995, p. 49.

${ }^{7}$ Ibidem, p. 56.

${ }^{8}$ HEIDEGGER, M. Nietzsche I. Rio de Janeiro: Forense Universitária, 2007, p. 98.

${ }^{9}$ Ibidem, p. 100.

${ }^{10}$ NUNES, B. "A destruição da estética e a modernidade”. lin: Hermenêutica e poesia, v. 9 (1999).

${ }^{11}$ ANDRADE, M. "Oswald de Andrade: Pau Brasil Sans Pareil, Paris, 1925". In BATISTA, M. R.; LOPEZ, T. P. A.; LIMA, Y. S. (orgs.) Brasil: 10 tempo modernista - 1917/29, documentação. São Paulo: IEB/USP, 1972, p. 230.

${ }^{12}$ GREENBERG, C. "Entrevista com Clement Greenberg”. IIn: FERREIRA, G.; COTRIM, C. (orgs.) Clement Greenberg e o debate crítico. Rio de Janeiro: Jorge Zahar, 2001, p. 145 